\title{
OPTIMUM CUTTING WIRE ASSEMBLY IN DIMENSION STONE QUARRIES
}

\author{
R. Bagherpour ${ }^{1}$, A. Khademian ${ }^{1, \#, ~ S . N . ~ A l m a s i ~}{ }^{1}$, M. Aalaei ${ }^{2}$ \\ ${ }^{1}$ Isfahan University of Technology, Department of Mining Engineering, Isfahan, Iran \\ ${ }^{2}$ Ahrar Sepahan Co, Ahrar building, Baborrahme Ave, Isfahan, Iran
}

(Received: February 24, 2014; Accepted: May 27, 2014)

\begin{abstract}
Production process in dimension stone quarries has a close relationship with the diamond beads efficiency and their number in unit length (density parameter). This study intends to find out the governing relationship between these parameters and cutting efficiency according to empirical findings in Targh travertine quarry. In addition, it's been tried to figure out the optimum operating condition in order to maximize the efficiency. To do so, along with the number of beads in unit length, other parameters such as cutting length and time have been recorded through the whole lifetime of cutting wire. The collected data have been compiled statistically in order to obtain the optimum cutting dimensions, cutting capacity and efficiency and the optimum number of beads in unit length. The results showed that the optimum mode of cutting wire assembly occurs using 31 diamond beads per meter. Besides, diamond beads have the highest efficiency at the middle third of their lifetime.
\end{abstract}

Key words: diamond bead, dimension stone, travertine quarry, cutting efficiency.

\section{Introduction}

Selection of mining method in exploitation of dimension stone is usually based on parameters such as physical, mechanical, textural and geological characteristics of rocks, blocks exploitability and production capacity. Nowadays, nearly all of travertine quarries are being exploited by diamond wire cutting method. Since the costs of cutting wire constitute a big portion in exploitation costs, its optimization can lead to great improvements in mining economy. So, in order to minimize the operational costs, some investigations about the optimum cutting parameters are essential.

The important point on efficient usage of diamond wire cutting is to produce blocks at minimum cost by adjusting the effective cutting parameters adequately [13]. These parameters can be divided in two groups; controllable and uncontrollable.

Uncontrollable parameters consist of physical and mechanical properties, geology and fabric of rocks and the climate conditions. Controllable parameters are mainly in relation to heavy machineries (such as cutting and boring machine) performance. One can change the controllable parameters by changing the designs and decision, but uncontrollable parameters cannot be changed by human being. Parameters that can affect cutting efficiency are given in table 1 [8].

After determination of uncontrollable parameters, one can achieve a suitable cutting process with modifying controllable parameters. There have been some studies in order to reply how each of these parameters can affect cutting process.

${ }^{\#}$ Corresponding author: Amir.khademian@mi.iut.ac.ir 
R. Bagherpour et al. / JMM 50 A (1) (2014) 1 - 8

Table 1. Effective parameters of diamond wire saw exploitation performance [8]

\begin{tabular}{lll}
\hline \multicolumn{1}{c}{ Uncontrollable parameters } & \multicolumn{2}{c}{ Controllable parameters } \\
\hline Rock properties & \multicolumn{1}{c}{ Cutting machine properties } & Operating conditions \\
\hline - hardness & - Machine power & • Technical personnel \\
- strength & - Machine position on either vertical & • Vibration of machine \\
- Water content & or horizontal cutting & \\
- Degree of alteration & - Number of beads per meter & \\
- Discontinuities & - Cutting angel between wire and \\
- Mineralogical properties & horizontal level \\
- Textural characteristics & - Amount of cutting area with respect \\
& to angel variation \\
& - Wire speed & \\
& - Amount of water used & \\
& - Bead structure & \\
\hline
\end{tabular}

Burgess correlated sawability to hardness, abrasion resistance, grain size and mineralogical composition [3]. Regression analysis showed that high correlations exist between specific energy and uniaxial compressive strength, Shore and Schmidt hardness, bulk density, apparent porosity, and flexural strength. However, Bayram believes that Cone indenter hardness, Shore hardness, and brittleness are the dominant properties for prediction of sawing performance in marbles [2]. Ertingshausen studied on the power consumption during granite cutting in upcutting and down-cutting modes [4]. Jennings and Wright carried out a general evaluation on affecting parameters on sawing performance. They concluded that small diamond grains must be used in hard rock cutting [5]. Ozcelik completed extensive researches on diamond wire saw method.

Ozcelik and Kulaksiz studied the relationship between cutting angle and wear of beads in diamond wire method [11]. They also investigated the wear of diamond beads in cutting process for different rock types with ridge regression [12]. Ozcelik worked on the optimum working conditions of cutting machines for marble rocks [9]. Also, he studied on the relation between textural characteristics of rocks and their sawability with diamond-mounted saws [10]. Ataei et al. used a statistical analysis to develop a prediction model for production rate of diamond wire saw method [1]. Mikaeil et al. found a mathematical relation between production rate and rock brittleness indexes for stone sawing in rock processing plants [6].

Among controllable parameters there is a parameter linked to cutting wire structure that is number of diamond beads in unit length. There is no significant investigation on this parameter and its effects in previous researches. This article investigates the influence of diamond beads density on cutting efficiency through experiments in real operating scale (in quarry). Beads performance has been investigated and analyzed in three time periods; beginning, middle and end of their lifetime.

For determining the optimum number of beads in wire assembly, the diamond beads efficiency calculations were carried out firstly by fixed cutting dimension and wire length but different number of beads. Then, the cutting dimension was kept fixed but the wire length and diamond beads density varied to find out the impact of these controllable parameters on quarrying. The acquired data has been processed and eventually some diagrams have been proposed for selection of optimum condition. Whole of these studies have been carried out in an operating 
travertine quarry in Iran belonging to Ahrar -e- Sepahan Company.

\section{Geological and geographical situa- tion of the Quarry}

This travertine quarry is located in Isfahan province near Natanz city that has geographical coordinate of 39 S 572979 3692785 in (WGS 84) UTM system. It lies near Natanz road, after Yahia Abad and Targh villages. There are some active springs in the region that all of them are located on top of travertine structures and some of them are up to $75 \mathrm{~m}$ higher than water stream beds. These travertine rocks are a part of Urmia-Dokhtar (northwest- southeast) zone and have 1 or 2 $\mathrm{km}$ distance from some active faults. According to these faults, the main formation factor of the deposits is the local tensions in overlapped sheet of the faults. The morphology of the quarry can be classified in fissure-ridges category which belongs to quaternary period. Some special characteristics such as ploidy pattern, laminations and stromatolite forms in sediments are all evidences that high biological and microbial activity occurs simultaneously with travertine sedimentation [14]. The main lamination type of travertine in this quarry is plane and it has stromatolitic microfacies. Among different identified types of porosities in the quarry, vuggy and secondary fracture porosities can be recognized [7]. Geological evidences show that these rocks have formed by tectonic magmatic activities in a geothermal gradient environment.

\section{Exploiting by diamond wire saw}

Diamond wire cutting machines have been used in marble industry since 1985 and have affected the production rate and efficiency considerably [12]. Today, they are widely used in more than $90 \%$ of the natural stone quarries [16]. In diamond wire cutting machines, cutting process takes place through some abrasive diamond wires.

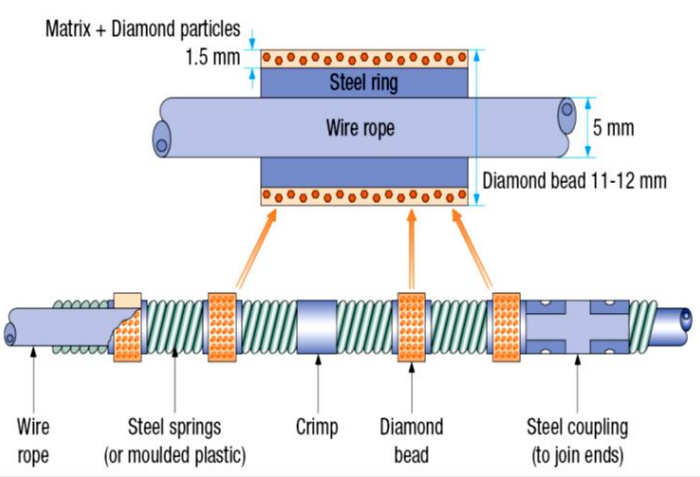

Figure 1. Schematic view of diamond cutting wire method and cutting wire [10]

The diameter of diamond wire saw and steel cable are $10-12 \mathrm{~mm}$ and $5 \mathrm{~mm}$ respectively. Number of beads varies between 30 and 35 in one meter of the wire that makes intervals between 25 and $32 \mathrm{~mm}$. Determination of optimum number of these beads in unit length is among goals of this article. Controlling of cutting machine parameters such as rotation, tension force and speed is performed through an automatic control panel. An electrical engine supplies the force of cutting machine and makes a 
drive wheel to rotate the diamond wire. Whole of cutting machine is mounted on a rail which enables the machine to move back and forward. Figure 1 illustrates a schematic view of diamond wire cutting method and cutting wire.

\section{Calculation of bead's cutting capa- city and efficiency for blocks with various dimensions}

The amount of rock surface cut by an individual diamond bead is called cutting capacity of bead which depends on mechanical characteristics of rock, bead quality and operator skills. In order to assess this parameter and optimize the block dimension based on maximizing the efficiency by lowering the beads consumption, data are collected during a period of 10-month of the travertine quarrying.

During all stages of this experimental study, a single type of cutting machines with the same operating parameters has been used.

Table 2. operational parameters of cutting machine

\begin{tabular}{lc}
\hline \multicolumn{1}{c}{ Parameter } & Description \\
\hline Main motor power & $45 \mathrm{KW}$ \\
Wire peripheral speed & $30 \mathrm{~m} / \mathrm{s}$ \\
Voltage & $440 \mathrm{~V}$ \\
Pulley diameter & $600 \mathrm{~mm}$ \\
Pull-back force (thrust) & $930 \mathrm{~N}$ \\
\hline
\end{tabular}

The operational characteristics of this cutting machine have been reported in table 2 . Also, all of investigation has been carried out on the same rock with the same mechanical characteristics. In other words, all of the affecting parameters were remained constant except the targeted parameter.

Based on quarrying of 290 blocks in this period, beads with three densities 1530,1260 and 1140 has been used for blocks dimension between 48 and 144 square meters. These blocks have been divided into 3 parts based on their cutting surface, namely small (48 to 64 $\mathrm{m}^{2}$ ), medium (70 to $90 \mathrm{~m}^{2}$ ) and large blocks (120 to $144 \mathrm{~m}^{2}$ ). Cutting rate and cutting capacity of the beads have been recorded during all of these cuttings. Table 3 shows a summary of observations considering the relation between consumed bead numbers and cutting rate. As it can be seen, for all of cases, cutting capacities are from 6 to 6.19 square meters. The main finding of these results is that the optimum (maximum) cutting capacity could be achieved by the mean dimensions of the blocks.

It is expected for cutting beads to have the highest cutting rate and efficiency during first stages of their lifetime. To investigate this phenomenon, the lifetime of diamond beads has been divided in three parts and cutting rate has been recorded for each part individually. Observations showed another important finding showing various beads performance in different cutting periods including first third, middle third and the final third. A summary of these findings has been reported in table 4 .

Table 3. Relation between consumed beads number, cutting rate and cutting capacity

\begin{tabular}{ccccccc}
\hline $\begin{array}{c}\text { Number of } \\
\text { cuttings }\end{array}$ & $\begin{array}{c}\text { Number } \\
\text { of beads }\end{array}$ & $\begin{array}{c}\text { Cutting } \\
\text { surface }\left(\mathrm{m}^{2}\right)\end{array}$ & $\begin{array}{c}\text { Total cutting } \\
\text { surface }\left(\mathrm{m}^{2}\right)\end{array}$ & $\begin{array}{c}\text { Total cutting } \\
\text { time }(\mathrm{h})\end{array}$ & $\begin{array}{c}\text { Bead efficiency } \\
\text { or cutting rate } \\
\left(\mathrm{m}^{2} / \mathrm{h}\right)\end{array}$ & $\begin{array}{c}\text { Bead cutting } \\
\text { capacity } \\
\left(\mathrm{m}^{2}\right)\end{array}$ \\
\hline 69 & 1530 & 120 to 144 & 9180 & 1510.75 & 6.1 & 6 \\
\hline 98 & 1260 & 70 to 90 & 7800 & 1236.5 & 6.3 & 6.19 \\
\hline 122 & 1140 & 48 to 64 & 6968 & 1072.5 & 6.5 & 6.11 \\
\hline
\end{tabular}


Table 4. Beads performance in different periods of their lifetime

\begin{tabular}{ccccccc}
\hline $\begin{array}{c}\text { Number of } \\
\text { Cuttings }\end{array}$ & $\begin{array}{c}\text { Number of } \\
\text { beads }\end{array}$ & Bead lifetime & $\begin{array}{c}\text { Cutting } \\
\text { surface }\left(\mathrm{m}^{2}\right)\end{array}$ & $\begin{array}{c}\text { Total } \\
\text { cutting } \\
\text { surface }\left(\mathrm{m}^{2}\right)\end{array}$ & $\begin{array}{c}\text { Total } \\
\text { cutting time } \\
\text { (h) }\end{array}$ & $\begin{array}{c}\text { Bead } \\
\text { efficiency or } \\
\text { cutting rate } \\
\text { (m } / \mathrm{h})\end{array}$ \\
\hline 23 & 1530 & First third & 120 to 144 & 3096 & 518.5 & 5.97 \\
\hline 23 & 1530 & Middle third & 120 to 144 & 3108 & 455 & 6.83 \\
\hline 23 & 1530 & Final third & 120 to 144 & 2976 & 537.25 & 5.54 \\
\hline 33 & 1260 & First third & 70 to 90 & 2640 & 417.75 & 6.32 \\
\hline 33 & 1260 & Middle third & 70 to 90 & 2680 & 386.25 & 6.94 \\
\hline 33 & 1260 & Final third & 70 to 90 & 2480 & 432.5 & 5.73 \\
\hline 41 & 1140 & First third & 48 to 64 & 2312 & 360 & 6.42 \\
\hline 41 & 1140 & Middle third & 48 to 64 & 2416 & 362.25 & 6.67 \\
\hline 41 & 1140 & Final third & 48 to 64 & 2240 & 350.25 & 6.40 \\
\hline
\end{tabular}

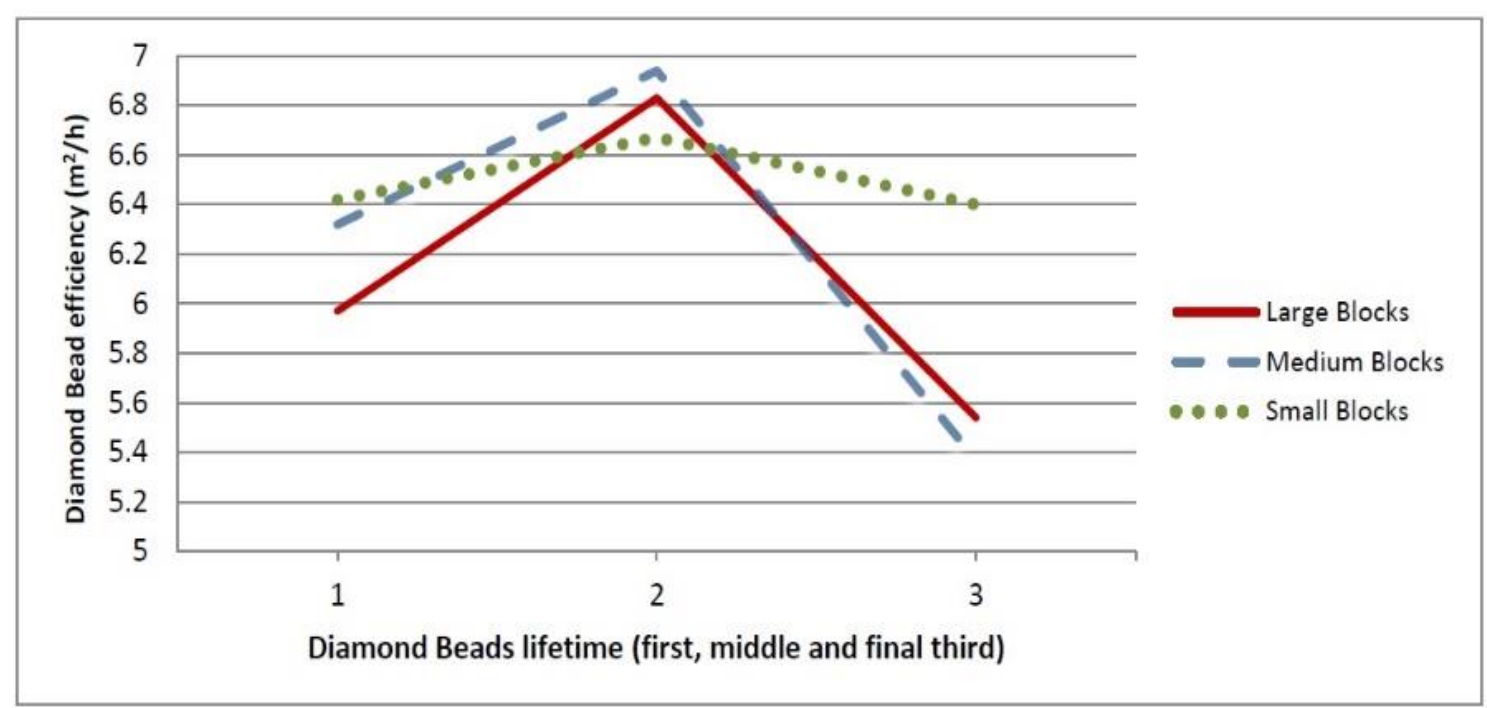

Figure 2. Beads performance in their lifetime for different kind of blocks

According to figure 2, in any case, middle third of beads lifetime produces highest efficiency and the first and final thirds are behind respectively. It seems that sharp corners of beads at the first stages of cutting could be the reason of such behaviour.

It can be concluded from table 3 and figure 2 that in block dimension selection, the medium dimension possesses the first priority, then small and large dimensions respectively. Also, as the block dimension decreases, the influence of diamond beads lifetime on the efficiency becomes negligible, but, while the dimensions are medium or large this parameter has a significant effect.

\section{Influence of the number of beads in unit length on cutting wire efficiency}

Besides other parameters, number of beads in unit length can also affect cutting efficiency (table 1). It is possible to find the optimum 
number of beads in unit length through some experiments. Cutting efficiency will be lower than optimum if the number of beads in unit length is more or less than a certain amount, both affecting the efficiency negatively. For the first situation, whereas beads number is more than optimum number, reduction of efficiency is due to high compaction of springs that makes high rigidity within the wire. For the other situation, when the beads number is less than optimum number, the clearance between components leads to both reducing the wire efficiency and increasing of wire rupture possibility. Tables 5, 6 and 7 summarize observations in travertine quarry with four different numbers of beads situations including 29, 30, 31 and 32 beads in unit length.

Table 5. Cutting wire efficiency for different number of beads in blocks with cutting surface of $80 \mathrm{~m}^{2}$

\begin{tabular}{ccccccc}
\hline $\begin{array}{c}\text { Number of } \\
\text { Cuttings }\end{array}$ & $\begin{array}{c}\text { Number of } \\
\text { beads per } \\
\text { meter }\end{array}$ & $\begin{array}{c}\text { Wire length } \\
(\mathrm{m})\end{array}$ & $\begin{array}{c}\text { Cutting } \\
\text { surface }\left(\mathrm{m}^{2}\right)\end{array}$ & $\begin{array}{c}\text { Total } \\
\text { cutting } \\
\text { surface }\left(\mathrm{m}^{2}\right)\end{array}$ & $\begin{array}{c}\text { Total } \\
\text { cutting time } \\
(\mathrm{h})\end{array}$ & $\begin{array}{c}\text { Cutting wire } \\
\text { efficiency or } \\
\text { cutting rate } \\
\left(\mathrm{m}^{2} / \mathrm{h}\right)\end{array}$ \\
\hline 6 & 29 & 42 & 80 & 480 & 84.75 & 5.66 \\
\hline 6 & 30 & 42 & 80 & 480 & 77.75 & 6.17 \\
\hline 6 & 31 & 42 & 80 & 480 & 77.25 & 6.21 \\
\hline 6 & 32 & 42 & 80 & 480 & 77.25 & 6.21 \\
\hline
\end{tabular}

Table 6. Cutting wire efficiency for different number of beads in blocks with cutting surface of $64 \mathrm{~m}^{2}$

\begin{tabular}{ccccccc}
\hline $\begin{array}{c}\text { Number of } \\
\text { Cuttings }\end{array}$ & $\begin{array}{c}\text { Number of } \\
\text { beads per } \\
\text { meter }\end{array}$ & $\begin{array}{c}\text { Wire length } \\
(\mathrm{m})\end{array}$ & $\begin{array}{c}\text { Cutting } \\
\text { surface }\left(\mathrm{m}^{2}\right)\end{array}$ & $\begin{array}{c}\text { Total } \\
\text { cutting } \\
\text { surface }\left(\mathrm{m}^{2}\right)\end{array}$ & $\begin{array}{c}\text { Total } \\
\text { cutting time } \\
(\mathrm{h})\end{array}$ & $\begin{array}{c}\text { Cutting wire } \\
\text { efficiency or } \\
\text { cutting rate } \\
\left(\mathrm{m}^{2} / \mathrm{h}\right)\end{array}$ \\
\hline 6 & 29 & 37 & 64 & 384 & 69.75 & 5.51 \\
\hline 6 & 30 & 37 & 64 & 384 & 65.5 & 5.86 \\
\hline 6 & 31 & 37 & 64 & 384 & 62 & 6.19 \\
\hline 6 & 32 & 37 & 64 & 384 & 62.25 & 6.17 \\
\hline
\end{tabular}

Table 7. Cutting wire efficiency for different number of beads in blocks with cutting surface of $48 \mathrm{~m}^{2}$

\begin{tabular}{ccccccc}
\hline $\begin{array}{c}\text { Number of } \\
\text { Cuttings }\end{array}$ & $\begin{array}{c}\text { Number of } \\
\text { beads per } \\
\text { meter }\end{array}$ & $\begin{array}{c}\text { Wire length } \\
(\mathrm{m})\end{array}$ & $\begin{array}{c}\text { Cutting } \\
\text { surface }\left(\mathrm{m}^{2}\right)\end{array}$ & $\begin{array}{c}\text { Total } \\
\text { cutting } \\
\text { surface }\left(\mathrm{m}^{2}\right)\end{array}$ & $\begin{array}{c}\text { Total } \\
\text { cutting time } \\
(\mathrm{h})\end{array}$ & $\begin{array}{c}\text { Cutting wire } \\
\text { efficiency or } \\
\text { cutting rate } \\
\left(\mathrm{m}^{2} / \mathrm{h}\right)\end{array}$ \\
\hline 6 & 29 & 33 & 48 & 288 & 53.75 & 5.36 \\
\hline 6 & 30 & 33 & 48 & 288 & 49.5 & 5.81 \\
\hline 6 & 31 & 33 & 48 & 288 & 48 & 6 \\
\hline 6 & 32 & 33 & 48 & 288 & 49 & 5.88 \\
\hline
\end{tabular}

As can be seen in figure 3 , situations where beads density are 30,31 and 32 for large blocks and 31 and 32 beads density for medium blocks will produce the highest efficiencies. But for the case of small blocks, highest efficiency only belongs to the case where 31 beads are mounted on a meter of wire. Effect of reduction in beads compaction 
and wire rigidity; when the block dimension increases, may be the reason for this phenomenon. However, regardless of block size, the optimum number of beads in unit length equals to 31 and if one wants to choose between 30 and 32, the latter is more efficient for all kind of blocks. Though, as figure 3 shows, it must be emphasized that the optimum situation of cutting wire assembly occurs by using 31 beads in unit length.

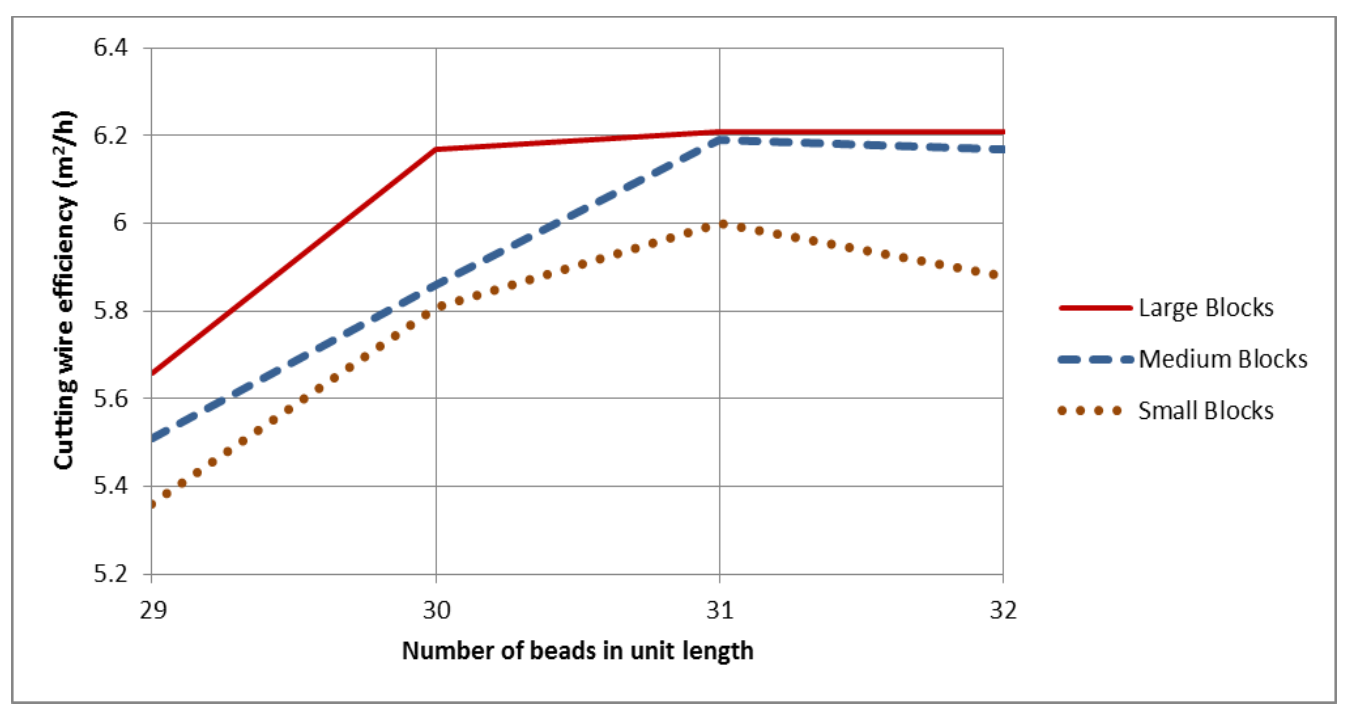

Figure 3.Cutting wire efficiency with different number of beads

\section{Conclusions}

Focusing on diamond beads role in cutting process as well as studying on some other operational conditions in Targh travertine quarry and detailed analysis on them, derived following conclusions:

- It is expected for cutting beads to have the highest cutting rate and efficiency during first stages of their lifetime but multiple experiments made it clear that the middle third of beads lifetime produces the highest efficiency and the first and final thirds are behind respectively. It seems that sharp corners of beads at the first stages of cutting could be the reason of such behaviour.

- In order to increase diamond beads efficiency, it is suggested to select small cutting dimension at the first stages of beads lifetime, then dimension must increase with the time and eventually at the final third of beads lifetime, cutting dimensions ought to be decreased.

- Results showed that regardless of block dimensions, the optimum number of beads in unit length equals to 31 and if one wants to choose between 30 and 32 , the latter is a more efficient situation.

- Since in the diamond wire saw method, in addition to the bead number, some other parameters such as steel springs size and number, couplings and crimps can influence the cutting process efficiency, it is essential to investigate their effects in further and future studies.

- These results came up from observation on travertine rock and might be generalized for all kind of carbonate rocks. But further researches are required for igneous and metamorphic rocks. 


\section{Acknowledgment}

Authors would like to thank Ahrar -eSepahan Company for their great cooperation during this study.

\section{References}

[1] Ataei, M., Mikaiel, R., Sereshki, F., Ghaysari, N. (2011) Predicting the production rate of diamond wire saw using statistical analysis. Arabian Journal of Geosciences, 5, 1289-1295.

[2] Bayram, F. (2013) Prediction of sawing performance based on index properties of rocks. Arabian Journal of Geosciences, 6 , 4357-4362.

[3] Burgess, R.B. (1978) Circular sawing granite with diamond saw blades. In: the fifth Industrial Diamond Seminar, 3-10.

[4] Ertingshausen, W. (1985) Wear processes in sawing hard stone. Industrial Diamond Review, 5, 254-258.

[5] Jennings, M., Wright, D. (1989) Guidelines for sawing stone. Industrial Diamond Review, 49, 70-75.

[6] Mikaiel, R., Ataei, M., Yousefi, R. (2013) Correlation of production rate of ornamental stone with rock brittleness indexes. Arabian Journal of Geosciences, 5, 115-121.

[7] Nasr Isfahani, A., Raisi Dehkordi, M, (2008) Petrology of travertines of south of Milajerd (northwestern of Ardestan, Isfahan), Journal of Isfahan University, 34, 161-176.

[8] Ozcelik, Y. (1999) Investigation of the working conditions of diamond wire cutting machines in marble industry. Dissertation, Hacettepe University.
[9] Ozcelik, Y. (2005) Optimum working conditions of diamond wire cutting machines in the marble industry. Industrial Diamond Review, 1, 58-64.

[10] Ozcelik, Y. (2007) The effect of marble textural characteristics on the sawing efficiency of diamond segmented frame saws. Industrial Diamond Review, 1, 65-70.

[11] Ozcelik, Y., Kulaksiz, S. (2000) Investigation of the relationship between cutting angles and wear on beads in diamond wire cutting method. In: Mine Planning and Equipment Selection Symposium, Athens, 661-666.

[12] Ozcelik, Y., Kulaksiz, S., Cetin, M.C. (2002) Assessment of the wear of diamond beads in the cutting of different rock types by the ridge regression. Journal of Materials Processing Technology, 127, 392-400.

[13] Ozcelik, Y., Polat E, Bayram F, Ay AM (2004) Investigation of the Effects of Textural properties on Marble Cutting with Diamond Wire. International Journal of Rock Mechanics and Mining Science, 41, 228-234.

[14] Pentecost, A. (2005) Travertine. Springer, Netherland.

[15] Sengun, N., Altindag, R. (2013) Prediction of specific energy of carbonate rock in industrial stones cutting process. Arabian Journal of Geosciences, 6, 11831190.

[16] Yilmazkaya, E. (2007) Investigation of Some Factors Effecting Block Cutting with Diamond Wire Cutting Method. Dissertation, Hacettepe University. 